\title{
METHODS OF TEACHING ENGLISH TERMINOLOGICAL VOCABULARY FOR STUDENTS OF NON-LINGUISTIC SPECIALTIES
}

\author{
Dariga Baizdrakhmanova ${ }^{1}$, Madina Tussupbekova ${ }^{2}$ \\ ${ }^{1}$ L.N. Gumilyov Eurasian National University, Nur-Sultan, Kazakhstan \\ ${ }^{2}$ L.N. Gumilyov Eurasian National University, Nur-Sultan, Kazakhstan
}

ORCID ID iD: 0000-0002-1285-1959

\begin{abstract}
This article is devoted to the problem of teaching terminological vocabulary of the English language for non-linguistic specialties. The main attention in the work is focused on the development of methodological foundations for the assimilation of terminological units of non-linguistic specialties. The possession of lexical skills necessary for professional communication in a foreign language is analyzed. The author emphasizes that the introduction of terminological vocabulary is an integral system of introductory exercises that systematize and consolidate new terminological information.
\end{abstract}

\section{INTRODUCTION}

The modern period of development is characterized by changes in all spheres as social, economic, political and cultural. These changes put forward new requirements for higher education and professional training of future specialists to adapt to multicultural, multilingual environment for realization of personal and professional needs. Kazakhstan is considered as a trilingual country with Kazakh, Russian and English spoken by its citizens. Notably, each of these languages has its own status, Kazakh is a state language, Russian the language of intercultural communication and English an international one [Nazarbayev, 2017].

According to the requirements of time, proficiency in English is necessary for future specialists of various industries in their scientific and practical activities, communication with foreign partners, obtaining information, for self-education and professional growth. It is very important to form the skills of future specialists to work with literature in English in their chosen specialty, since it is the text that is one of the main means of replenishing professional knowledge. Any industry operates with certain terms. Therefore, the object of special attention is the study of special vocabulary - terms and their equivalents in the translation language. Knowledge of terminology helps not only to perform an adequate translation of a highly specialized text, but is also an integral part of the general competence of specialists in a particular industry.

The term is ambiguous. It is a unit of the terminological system and must have the above properties. At the same time, the term is a unit of the lexical system of the language and obeys the laws of the development of the word. This explains the presence, even in one terminological system, of the term polysemy and the appearance of synonymous terms. Terminological groups of different branches of science and technology interact, and often the term of one terminological group is used as a term in another group, and not necessarily with the same meaning [Zavarzina, 2019].

A terminological system is a subsystem of a language. The special and general systems are linked by two-way communication and are in constant interaction. Terms from a narrow sphere of use enter the lexical composition of common vocabulary and, conversely, common words are a constant source of term formation. The study of the terms of general technical, popular science and special literature is necessary at non-linguistic faculties: it would be advisable to introduce general concepts of terminological systems, terms and their properties into the course of teaching a foreign language. The term, as a rule, is unambiguous, stylistically neutral, systematic. Full certainty of the meaning and stability of use are mandatory requirements for it [Madsen, 2004].

It is very important to form the skills of future specialists to work with authentic texts in English. It is also necessary to note the importance of interdisciplinary ties: it is impossible to teach 
English in isolation from the core disciplines. Specialized materials often tell about phenomena, technical innovations and discoveries. Therefore, working with such authentic materials implies close cooperation between an English teacher and teachers of special disciplines. The assimilation of terminological vocabulary always presents one of the greatest difficulties for students, therefore, this article focuses on various ways to activate terminology for non-linguistic specialties. The vocabulary activation stage assumes that students are already familiar with a number of terms on a particular topic. At the stage of consolidation, a wide variety of exercises are used related to the assimilation of the meaning, form and use of words [Berardo, 2006].

\section{METHODS OF TEACHENING}

The work on the study of terminological vocabulary has its own specifics and represents one of the difficult problems of teaching English vocabulary for non-linguistic specialties. Its main goal is to assimilate the terminological vocabulary of this subsystem of the language, which allows not only to correctly perceive the text, but also to actively use words-terms when constructing their own statements in a communicative way. When developing methodological foundations for the study of terminological units of the specialty, first of all, this work should be included in an integrated system of work on the formation of linguistic (lexical) and speech skills. Thus, lexical skills are considered to be the ability to understand and correctly use terms in speech [Bidnenko, 2021].

One of the important tasks that should be solved when working on the study of the terminology of the specialty is to organize vocabulary so as to remove memory overload, so that each assimilated term-word helps to memorize and repeat the previous term. This was pointed out by I.D. Salistra, who believed that, determining the content of teaching a foreign language on the basis of speech orientation, it is necessary to understand what kind of speech material students should be able to operate with; what should be the approach to determining the sequence of assimilation of the material and the formation of appropriate skills [Smailova, 2021].

Memorization of the term begins from the moment of its presentation and is characterized by the fact that the associative connection created for a time between the image and the word can be fragile and quickly fade away. Whatever happens, it is necessary to support it with repeated repetition. The previously learned word-term must be included in new situations, contexts. At the same time, it is important to ensure that the word is repeated not in any one form, but in all the most commonly used forms. So that non-thematic and commonly used words are repeated in different speech forms, they are maximally mobilized when working on different topics, contributing to the creation of a conscious transference skill [Mazur, 1997].

Lexical skill at any level of proficiency in a language unit involves the development of a strong two-way relationship between form and meaning. This connection is achieved due to their repeated repetition, since the productivity of reproduction is determined, first of all, by the characteristics of the memorized material, the amount of information contained in it.

The work on the formation of terminological skills and abilities in relation to the terminological unit should be carried out in several stages:

- assimilation of a certain number of terms, their recognition, selection and comprehension in the text;

- active use of these words in the process of self-expression.

The main goal of the first stage is the assimilation of terminological vocabulary. To do this, it is necessary to create conditions for transferring existing lexical skills to terminological units. The main objectives of this stage are the formation of skills to distinguish terms from non-terms, to create conditions for mastering the terminology of the specialty. To do this, it is necessary to carefully select texts on the specialty from the position of the representation of terms and terminological combinations in them, to carry out their lexicographic development, which would contribute to the comprehensive assimilation of terminological words. In addition, a system of exercises and tasks should be developed that would help to effectively solve the tasks set [Bakirova, 2020].

Since the form and meaning of a word is assimilated due to situational relatedness and the need for expressing one's thoughts, the primary training in the use of new vocabulary after its 
presentation is carried out in conditional speech exercises (exercises for imitation, substitution, transformation, reproduction). Training in imitation allows students to create an auditory and visual image of the word based on sensations, which ensures the strength of memorization of formal signs of the word. Substitution exercises contribute to strengthening associative connections and develop the operation of calling a word. Also, question-and-answer exercises conducted in the form of a dialogue - questioning, guided dialogue, as well as game techniques with the proposed verbal support from the teacher are an effective technique for memorizing words.

The purpose of the next stage is the formation of specific terminological skills and abilities related to the development of these units; the formation of skills and abilities to identify terminological combinations in the text; the assimilation of the laws of the functioning of the term in the context, the position of the terminological unit in the process of utterance. In order to successfully solve these problems, it is necessary, in addition to careful selection of textual, lexicographic and other illustrative material, to present the main associations of terminological units; to present composite terminological combinations based on syntactic constructions; to acquaint students with the main functions of the term in these types of texts. Achieving this goal is possible provided that a system of exercises is developed.

Subsequent exercises related to the use of vocabulary at the reproductive level involve the use of new words in speech (with and without verbal supports). The attention of students when performing such exercises is directed both to the content and to the form. Such exercises can be creative in nature and contribute to the development of students' creative abilities. Exercises of this type include tasks to restore missing words in the text, instead of which pictures or pictograms.

The goal of the third stage is to master the highly specialized terms of the specialty, as well as professional turns of speech. The objectives of this stage are: the formation of skills and abilities for the use of highly specialized terminological units in speech; familiarity with the structure of the terminological system of the sublanguage; the formation of skills and abilities to analyze the morphological structure of a derived term; the assimilation of the most productive word-formation models; familiarity with the specifics of the functioning of the term; definition of the main areas of their application.

Such techniques as crosswords, composing words from letters and syllables, composing short words from a longer one, searching for a generalizing word in a chain of words, creating a new word by replacing one letter in a given word allow you to remember the formal signs of a word. A variety of game techniques, the purpose of which is to strengthen the connection between the image of the word and its meaning. These games are based on the principle of finding a pair, for example: wordpicture, word-translation, word-antonym, word-synonym, question-answer, riddle-guess. Of particular importance are language exercises aimed at strengthening associative connections, specifying the content and scope of the concept, forming and improving the action of combining a new word with others. These include exercises to search for a common word or superfluous in a chain of words, search for an object by given signs, for correlation, filling in an associogram. These stages consider the introduction of terminological vocabulary not as a one-time systematization, but as an integral system of introductory exercises that systematize and consolidate new terminological information [(Nikolayenko, 2015].

One of the most important prerequisites for the development and improvement of English speech among students is the development of skills, skills and determination of word combinations, the structure of phrases, the ability to use terminological words. The perception of English speech is carried out more successfully and more freely if students of non-linguistic specialties identify and realize grammatical and lexical elements in it, establish logical connections and relationships between words, understand the variety of words, forms and constructions of the studied language.

\section{DISCUSSION}

The main goal was to find the best method for studying terminological vocabulary for non-linguistic specialties. Studying articles on this topic, I managed to find answers to the questions of my research: students demonstrated good results in studying terminology in professionally oriented and 
meaningful tasks that were interactive in their origin, such as discussions, role-playing games, modeling and presentations of their written reports. There is a direct relationship between the use of terminological vocabulary and the quality of training: the more terminology is used in the classroom, the better the results. As it was revealed during the review of articles, the use of terminological vocabulary should be systematically used in all types of speech activity, which can ensure effective assimilation of educational material, as well as increase the ability of students. The students also noticed that the use of authentic sources for the selection of terminological vocabulary helps not only to increase vocabulary, but also develops communication skills. Exercises are one of the most important means of presenting language materials and forming lexical and grammatical skills and abilities, further improving them and transforming them into communication skills. Students need to be helped to master the vocabulary and correct terminological phraseology appropriate to their abilities if they want to succeed in the subject. Teachers should be aware that it is not easy to give a very precise definition of some terms in ordinary English and that such terms are best understood in their technical form. However, an alternative approach to defining terms would involve using appropriate relevant examples already known to students. Thus, using terminological vocabulary, students will learn new language units more effectively.

\section{CONCLUSION}

The above methods of mastering professional vocabulary can be modified, changed and supplemented depending on the specifics of the audience, the purpose and stage of training. Such exercises are good because they develop guesswork, increase practice in the language and create supports for memorizing terms, as well as strengthen associative connections. The assimilation of terminological vocabulary by the proposed methods is very effective, because it allows students to comprehend lexical units, see the relationships (similarities and differences) between words, create a support for their further use in various types of speech activity, organize independent work of students. Therefore, the object of special attention is the study of special vocabulary - terms and their equivalents in the translation language. Knowledge of terminology helps not only to perform an adequate translation of a highly specialized text, but is also an integral part of the general competence of specialists in a particular industry.

\section{REFERENCES:}

Bakirova, H. B. (2020). Teaching foreign language terminology at a non-language university. International scientific and technical journal "innovation technical and technology”, 1(2), 46-50.

Berardo, S. A. (2006). The use of authentic materials in the teaching of reading. The reading matrix, 6(2).

Bidnenko, N. P. (2021). To the problem of translating new terminological vocabulary. Publishing House "Baltija Publishing".

Madsen, B. N., Thomsen, H. E., \& Vikner, C. (2004, May). Principles of a system for terminological concept modelling. In $L R E C$.

Mazur, E. (1997). Understanding or memorization: Are we teaching the right thing. Conference on the introductory physics course on the occasion of the retirement of Robert Resnick (p.113-124).

Nazarbayev, N. A. (2017). Trinity of languages' - the base for multicultural personality, 54(9)

Nikolayenko, V. V. (2015). Learning of Russian terminology вy foreign students majoring in economics as a Key element of their professional competence, (26), 109-118.

Smailova, F., \& Zhapakov, S. (2021). Retrospective analysis of didactic principles and methods of teaching a foreign language, $1(1$ (75)), 374-379.

Zavarzina, G. A., \& Dankova, T. N. (2019). Actual problems of terminological system development of new state administration. In SHS Web of Conferences (Vol. 69, p. 00138). EDP Sciences. 